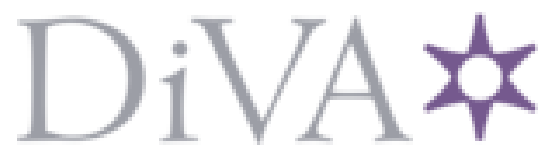

http://www.diva-portal.org

\title{
Postprint
}

This is the accepted version of a paper published in International Review for the Sociology of Sport. This paper has been peer-reviewed but does not include the final publisher proof-corrections or journal pagination.

Citation for the original published paper (version of record):

Johansson, S., Larsson, H. (2017)

'This might be him; the guy I'm gonna marry': Love and sexual relationships between female elite-athletes and male coaches.

International Review for the Sociology of Sport, 52(7): 819-838

https://doi.org/10.1177/1012690215626593

Access to the published version may require subscription.

N.B. When citing this work, cite the original published paper.

Permanent link to this version:

http://urn.kb.se/resolve?urn=urn:nbn:se:gih:diva-4303 


\section{'This might be him; the guy I'm gonna marry': Love and sexual relationships between female elite-athletes and male coaches}

Susanne Johansson and Håkan Larsson

\section{Abstract}

Infatuation, love, and sexual relationships exist virtually anywhere. Coach-athlete sexual relationships (CASR), however, are overlooked and under-researched. Within sport sociology, CASR have predominantly been framed by a sexual abuse discourse. Informed by Foucault's discourse analysis, this study explores how discourses regarding performance enhancement in elite-sport and coaching, and romantic love frame female elite-athletes' experiences with CASR. Interviews with four female elite-athletes aged 26-30 were conducted. The results indicate that CASR are potentially problematic because they intersect and challenge discourses comprising elite-sports, coach-athlete relationships, female sexual agency, and love. Moreover, discourses of power differ between the professional and private context. While the athletes expect their coaches to implement dominance and control in the elite-sport context, love relationships are about equally and mutually giving away power and control. Although CASR can facilitate motivation and performance, framing CASR as inherently unequal and abusive can contribute to stigmatisation, secrecy, and athlete disempowerment.

\section{Keywords}

Coach-athlete relationship, elite-sport, romantic love, sexual agency, sexual abuse

\section{Introduction}

In Sweden, coach-athlete couples of well-recognised female elite-athletes and their male coaches are occasionally reported on by the media. These public romantic relationships seem uncomplicated, uncontroversial and do not counter legal regulations, Swedish sport policy or 
social conventions regarding age, gender and sexuality. Meanwhile, romantic coach-athlete relationships are rarely noted in research. Instead, coach-athlete sexual relationships (CASR) are usually framed in terms of sexual abuse (Johansson, 2013). Toftegaard Støckel (2010:98) holds that '[c]oaches should be informed that there is no such thing as a romantic coachathlete relationship, and that coaches' physical or emotional advances are always wrong.' We believe, however, that framing CASR as inevitably abusive and wrong may be damaging to the well-being of both athletes and coaches - despite the intention to protect athletes' - and ultimately to sport in general. Similar to Sikes' $(2006,2010)$ reasoning about teacher-pupil sexual relationships, we suggest that normative notions of CASR as inherently harmful, abusive, and unethical disregards issues such as women's agency, female sexual desire, and mutual love by reproducing discourses of power framing female athletes as victims of male perpetrator coaches.

In this study our intention is to analyse the contexts of CASR by including discourses that has previously been disregarded, from a perspective that do not cast CASR as inherently abusive or as either right or wrong per se. More specifically, the purpose is to explore how discourses regarding performance enhancement in elite-sport and coaching, and romantic love frame female elite-athletes' experiences of CASR. We define CASR as couple relationships and casual sexual relationships between athletes and their coaches. The coaches and athletes are at least 18 years old and the CASR are legal by law. CASR include lesbian, gay, and straight relationships, but the relationships explored in this study are heterosexual. The current topic as well as our approach may be perceived as provocative, but we believe this is precisely why CASR needs to be comprehensively investigated from multidimensional perspectives (cf. Lee, 1993; Sikes, 2006). Our ambition is, however, to practice caution, responsibility, and respect, and to acknowledge the ethical concerns, complexities, and sensitivities that arise. We hope that the present study can go some way to balance the understanding of CASR and illustrate relevance for further study. We moreover suggest that framing CASR as inherently unequal and abusive is one-dimensional, negates female sexual agency and may disempower female athletes. Coaches may, in turn, be given a position as subjects both of sport and sexual desire, which can be damaging too. Instead we advocate a climate of openness, dialogue, education, and transparency in sports (and research) regarding CASR. Hopefully that can contribute to improve the conditions for CASR and prevent sexual abuse. 


\section{Contextualising coach-athlete sexual relationships}

This study draws on Foucault's insights into the relationships between power, knowledge and subjectivity (Foucault, 1998). In an investigation into the history of sexuality, Foucault highlighted how power, knowledge and subjectivity are interrelated in discursive practice. That is, in the sense that repressive power orders contribute not only to produce knowledge about 'deviant behaviour' but also, albeit unintentionally, to engender stigmatisation of both (male) 'perpetrators' and (female) 'victims' (Foucault, 1979; see also Garratt, et al., 2013 on the 'politics of touch' in sport). By using Foucault's notion about the interrelatedness of power, knowledge, and subjectivity, we intend to explore CASR from a perspective where prohibition and repression, and hence possible stigmatisation of 'deviant' coaches, athletes, and relationships, is not the given starting point.

Foucault saw as his overarching endeavour to investigate the 'different modes by which, in our culture, human beings are made subjects' (Foucault, 1982: 208). This is the result of human beings subjecting themselves to the structural relationships of discourses, alternatively referred to as normalising processes (Foucault, 1977; 1979). The subjection engenders experience, intentionality, desire, hence also the conditions for transgressing 'the order of things.' Agency is, in Foucault's thinking, not outside of or the opposite to power. Rather, subjectification is a necessary condition for the possibility of experiencing agency.

In everyday language, discourse designates the verbal interchange of ideas where focus is on the ideas that are verbally articulated (Larsson, 2014). Foucault, however, held that focus should not be on 'ideas' but on the 'interchange,' or, more specifically, on the practice of interchange: what the practice of interchange makes real and how subjects (and objects) are formed through discursive practice (Foucault, 1998). In this article, we explore how female athletes negotiate performance enhancement discourse in elite-sport and coaching, and discourses about romantic love. These discourses were evoked as the first author urged the athletes to speak about their elite-sport experiences more broadly and about their CASR specifically.

\section{Sexual relationships and abuse}

Within the current literature, CASR has primarily been associated with sexual abuse; focusing on non-consensual, ambiguous sexual relationships and sexual abuse of minors (Bringer et al., 2002, Johansson, 2013). Sexual abuse can be broadly defined as any unwelcomed, nonconsensual, or underage sexual activity (Johansson, 2013). The main focus in the research to 
date may be related to a male/perpetrator - female/victim paradigm (Hartill, 2009), and to children as incapable to consent to sexual activities and unable to comprehend sexual misconduct such as harmful, inappropriate physical touch (Brackenridge, 2001; Johansson, 2013; Piper et al., 2012). Nevertheless, the sexual abuse perspective on CASR also illustrates its own merits; sexual consent can be highly complex, not the least in sexual relationships between coaches and athletes. It has been found that coach-athlete relationships can facilitate abuse by blurring boundaries and complicating sexual consent (Brake, 2012; Toftegaard Nielsen, 2001). Coaches may, for example, groom athletes by abusing their positional power and athletes' trust, infatuation, and love to facilitate isolation and eventually sexual abuse. In such cases experiences of sexual activities can be renegotiated as time pass, especially adults looking back at their experiences from childhood and adolescents (Fasting and Sand, 2015). Some argue that asymmetric power incapacitates female athletes, and women in subordinate professional positions generally, to consent to sexual activities all together (cf. Brake, 2012; Kirby et al., 2000; Lane, 2006).

From what is said so far, it might seem reasonable that CASR are broadly condemned and prohibited to protect athletes of all ages from sexual abuse-which a growing number of sport organisations do (e.g., ICCE, 2012; Safe4Athletes, 2013). As a related example, sexual relationships between licensed psychologists and clients is broadly prohibited and strictly regulated by legal authority to protect the welfare of the clients (APA, 2010). Johansson (2013:15) claims, however, that 'There is no evidence to suggest that prohibition reduces the number of coach-athlete sexual relationships, or the prevalence of sexual abuse.' Sexual abuse has moreover been found to be equally prevalent inside sport as outside it (Fasting et al., 2003; Leahy et al., 2002). In that sense sport is not a particularly dangerous environment compared with other social settings. In his study Toftegaard Støckel (2010) found that a majority of coach-athlete intimate relationships were reported to be positive and involving athletes of legal age. In addition, discourses of 'harmful touch' and coaches and 'dangerous individuals' has prompted extended surveillance, regulation, and mistrust of coaches, which in turn have been found to harm coaches, coaching, coach-athlete interaction, and ultimately contribute to an unhealthy social environment in sport (e.g., Garratt et al., 2013; Piper et al., 2012; Taylor et al., 2014). These findings does not take away the importance to prevent sexual abuse, but they imply that it can be inaccurate, and sometimes even harmful, to principally lump CASR together with sexual abuse. 
Another way to frame CASR is to emphasise agency, especially female sexual agency. Sikes (2006) studied female secondary school students and male teachers who fell in love with each other. By letting them voice their experiences Sikes wishes to 'offer an alternative view of gendered sexual agency and the exercise of power that does not cast women as the passive recipients of active male desires and the inevitably weaker and harassed party in any relationship' (2006: 267). Similar to CASR, these relationships tend to be associated with inequality, abuse, taboo, and scandal in response to dominant discourses on gender, sexuality, and power, resulting in a male/teacher/predator-female/student/victim dichotomy (cf. Hartill (2009) in previous section). Sikes suggests that because of the taken-for-granted power differential between teacher and student, a dominant discourse casts sexual relationships between them as abusive and inevitably wrong. Although Sikes acknowledges structural power, her research illustrates that the dimensions of power within a relationship does not one-sidedly favour the male teacher, negate female pupils' sexual agency, or the possibility of a consensual, long-term relationship. The problems the couples in Sikes' study faced had to do with moral prohibitions and normative notions resulting in stigmatisation, secrecy, forced break-ups, and inadequate interventions by families and school administration.

There is no simple, uniform right or wrong solution to legal sexual relationships that involve asymmetric power between professional parties (e.g., at workplaces, schools, and universities). Although authority-subordinate sexual relationships can include both positive and negative characteristics, they tend to pose dilemmas (e.g., Bringer et al., 2002; Sikes, 2006; Williams et al., 1999). Prohibitive policy can contribute to dilemmas because they may send the message that such relationships are unethical and suspect, which hamper transparency and necessitates authority-subordinate sexual relationships to be kept closeted to avoid problems (Powell and Foley, 1998). This results in a self-fulfilling prophecy: The couples are driven to keep their relationship secret and private, and thus they fulfil the stereotypical picture of such relationships as being clandestine, furtive and too sordid to reveal. Keeping sexual relationships secret because they are not socially accepted have been found to be an unhealthy solution (e.g., Lehmiller, 2012). Another problem can be that policies are ignored, much due to a lack of knowledge (Toftegaard Nielsen, 2001). By giving voice to female athletes' experiences of legal and consensual CASR we, similarly to Sikes (2006, 2010), wish to offer a counter narrative that challenges the dominant sexual abuse discourse. 


\section{The sociology of love}

Infatuation and love exist in virtually every society and social setting-including sports. In the present study we explore discourses of romantic love that are fundamental and firmly ingrained in Western culture; highly exposed in popular culture, fairy-tales, and other forms of narratives that can include features such as 'heartache', 'forbidden love', and 'happily ever after' kind of love (Felmlee and Sprecher, 2006; Jackson, 1993; Jackson, 2001). Discourses of love typically depict strong emotions outside the rational discourse, knowable intuitively through feelings (Jackson, 1993; Jackson, 2001). The intense, overpowering emotions when 'falling in love' are often deemed a strong force. For example, Sarsby (1983: 5-6) describes:

Love is seen as the bolt from the blue against which one cannot struggle, the pre-ordained meeting of twin souls, the compulsion which allows one to break any of society's rules as long as one is faithful to the emotion itself.

Due to the potential force and pervasiveness of love, there is a need to mediate, control, and regulate its meanings and outcomes to reproduce social structure. From a sociological perspective, the meaning and experience of love is mediated by culture, language, and subjective experience. Appropriate romantic love relationships meet the social conventions of a given context and are implemented by cultural institutions such as marriage and family (Felmlee and Sprecher, 2006; Jackson, 1993). In the present study we focus on discourses of a romantic kind of love that is typically sexual, often recognised as the outcome of 'falling in love' (Felmlee and Sprecher, 2006; Jackson, 1993), and that has been previously disregarded or limited to a context of grooming in the current research (Johansson, 2013). In feminist theory, sexuality and love has been viewed as ideology - a tool to control and subordinate women, female sexual agency, and desire. For example, women engaging in 'non-normal' sexual relationships, such as casual sex connections, risk a 'slut stigma,' whereas romantic love can legitimise women's sexual activity and serve as metaphor for sexual desire (Jackson, 1993; Jackson, 2001; Moran and Lee, 2014).

\section{Critically engaging with sport and coaching}

Athletes' experiences with CASR need to be understood in relation to contextual factors; what values that are ascribed to sport broadly, including beneficial aspirations such as health, performance, education, and personal development. Moreover, the norms that are foregrounded in elite-sport, particularly about what it takes to be a successful athlete (e.g., 
'sacrifices' related to eating, sleeping, social life outside of sport, family life, other hobbies, etc.). In particular, athletes' experiences with CASR must be understood in relation to the professional role of coaches more broadly, their function in sport, and ideas about 'effective coaching' to promote performance in elite-sports (e.g., Nicholls, 2013; Soucie, 1994).

Sport is broadly associated with positive values regarding physical, lifestyle, affective, social, and cognitive benefits (Bailey, 2006). Even though elite-sport can be unhealthy and is mainly about pushing limits to enhance performance (Brake, 2012; Kenttä, 2014), eliteathletes are often taken to be role models (Biskup and Pfister, 1999; Brown et al., 2003). According to Houlihan (2010), a common idea is that 'the magic dust of sport' has the potential to resolve problems ranging from obesity to juvenile crime. In Sweden, such beliefs rose in the post-WWII decades, as sport became the largest popular movement and started to receive funding through taxes (Norberg, 1997). The above mentioned tension between the beneficial aspirations linked to sport and the sacrifices that are taken to be a necessary ingredient for success is very much a reality in Swedish sport. All sport (children's sport, elite-sport, recreational sport, etc.) is organised within the framework of one organisation, which issues policy and has a semi-governmental status: The Swedish Sports Confederation (SSC). SSC's contemporary self-image is that it is 'open to all, independent, non-profit, democratic, based on voluntary leadership and work, dynamic, and a co-operating force in developing society' (SSC, 2012:5). Aspirations rather than facts, these features are nonetheless conventionally taken to be truths in relation to which individuals may deviate, but as a consequence of individual imperfection not as a consequence of sport itself, which is instead seen to be inherently good (Houlihan, 2010).

Being a coach is a celebrated position and the coach-athlete relationship is one of the most influential and important relationships in sport. Ideally, coach-athlete relationships are characterised by interdependency, safety, trust, closeness, and cooperation, where coaches' alleged knowledge, motivational skills, and concern serve as key links to athlete wellbeing, achievement and success (Jowett and Poczwardowski, 2007; Stirling and Kerr, 2009). Already in 1985, Parameswara (1985) noted that '[c] oach is the center of sports'. Later research has confirmed this position (Johns and Johns, 2000), not least because of the increasing professionalization of sports (Taylor and Garratt, 2010). Nonetheless, being at the centre of sports has at times proven to be an ambiguous position. From a critical perspective, being 'at the centre of sports', coaches are authorised to make decisions in the name of what is 'the best for an athlete'. With this legitimate authority comes a moral right—which is often 
recognised by athletes — not just to monitor athletes' training, but extends into personal domains including diet and social habits (Larsson, 2001; Stirling \& Kerr, 2009). In connection with (hetero)sexuality, the central position presumably means also that coaches' position as sexual (and potentially predatory) subjects is amplified, which can have certain gender implications since female elite-athletes are often coached by male coaches (Kenttä, 2014). Since sport is to some extent 'untouchable' (Anderson, 2010: 8), coaches who fail to live up to the high standards might however suffer a fall from grace. Thus, sport coaches are hailed downwind but scorned in headwind.

\section{Methodology}

To explore how athletes negotiate discourses the study uses a qualitative methodology drawing on semi-structured interviews. The current topic and events can be delicate, discrediting and taboo. Sexual relationships are typically private and research on sex and sexuality can be found intrusive, uncomfortable, and controversial (Renzetti and Lee, 1993). As such, sensitive research can entail challenges regarding honesty, disclosure, and, thus, the reliability of the data - even more so regarding sexual relationships that may threaten social conventions, morals, and professional standards (Lee, 1993; Renzetti and Lee, 1993; Sikes, 2010). Thus, ethical considerations such as confidentiality and sensitivity were paramount throughout the study, that has been approved by the Regional Ethical Review Board (No. 2011/669-31/5).

\section{Participants}

A generic purposive sample regarding CASR experience, accessibility, and assumptive wealth of information was selected (cf. Bryman, 2012). Due to the limited research on CASR we adopted some sample criteria from interview-studies with athletes investigating sexual and emotional abuse, in particular Stirling and Kerr (2009), together with our own considerations. Given the sensitive and private topic that complicated participant recruitment, most of the sample criteria was preferred rather than required. More specific sample criteria were:

1. CASR experience: A required criteria to enable participants to voice their own experiences was that they had been in CASR with their coaches during their athletic career (cf. Sikes, 2006). 
2. Time period: We tried to balance our request about experiences and presumed wealth of information with challenges of memory recall and potential benefits with having some distance to lived experiences, e.g., broader perspective, enhanced ability to reflect and perhaps re-define sexual consent given at a younger age (cf. Fasting and Sand, 2015; Stirling and Kerr, 2009). Thus, we preferred that the CASR experiences was no more than approximately five years back in time and to select athletes who had been coached by the specific coach for at least a few years, during which time the CASR developed. In addition, the sample includes both current athletes and retired athletes (i.e., that no longer competes in their sport).

3. Gender: Although we did not have an initial intention to limit the sample regarding gender, we did not find any male athletes with CASR experience and the female athletes that we recruited had all been in CASR with male coaches. We hypothesised that this gender homogeneity could facilitate contextualisation and operationalisation of the study (cf. Stirling and Kerr, 2009), and were thus content with the female athlete sample.

4. Elite-athletes (i.e., competing at national and/or international level(s)): We choose eliteathletes to have a more homogenous sample and because the coach-athlete relationship may be particularly influential on elite-level (cf. Stirling and Kerr, 2009).

5. Individual and team sports in Sweden (i.e., where athletes compete individually or in teams, respectively): We preferred to include athletes that represented both individual sports and team sports to be able to explore how the CASR affected the social dynamics in the athletes teams and in the more one-on-one coach-athlete relationship in individual sports (cf. Brake, 2012; Stirling and Kerr, 2009).

6. Athlete's age: Due to our intention to study legal CASR the athletes (and involved coaches) are of legal age of consent (accounting for both the general 15 year-old threshold and the 18 year-old minimum in specific relationships of trust to legal guardians and teachers according to Swedish law), but preferably well above 18 to enable an adult/young adult perspective. 
Consequently, the sample include current and retired female elite-athletes in individual and team sports, aged 26-30, who has been in CASR with their male coaches (details about the participants, their coaches, and relationships at the time of the interview can be found in Table 1). For the sake of confidentiality, the participants go under the pseudonyms of Mia, Anna, Ella, and Liv. The coaches' positions were head-coaches of clubs/teams, national-team coaches, and one assistant coach. Due to confidentiality, the coaches are not individually linked to each relationship.

\section{TABLE 1 ABOUT HERE}

\section{Procedure}

We used our social network within sports to cautiously initiate contact with potential participants. Athletes were first asked whether they would like more information about the study by a person they were familiar with (and had told about the CASR). The first contact between researcher and athletes was established via telephone and email. Detailed information about the study, the interview procedure, publication, and ethical considerations was presented in writing. Both researchers and athletes agreed that the participation was to be held confidential. The participants were informed that great measure was taken to prioritise confidentiality in attempt to minimise the risk of identification; that the interview could be terminated or paused at any time without repercussions; and that all topics were optional. All contacted athletes agreed to participate in the study, and they spontaneously responded that the topic came across as interesting and important.

For consistency and a trustworthy connection, the first author handled all participant interaction, and served as instrument to carry out and transcribe all (cf. Mero-Jaffe, 2011). The role of the interviewer was to facilitate a conversation flow, actively listen, guide, and be responsive to the interviewee (Bryman, 2012). The researcher, a woman of similar age and an elite-athlete herself, facilitated the interaction (cf. Lee, 1993). The interviews took place faceto-face in a private, undisturbed location that was chosen or approved by the. Before the interviews we talked about the study, the interview, and any related questions. An interviewguide with thematically organised topics related to the research aim and review of the current literature was formed as a 'brief list of memory prompts of areas to be covered' (Bryman, 
2012:472-473). The guide was tested in a pilot interview and turned out to serve its purpose with only a few minor additions made after evaluation. As the pilot interview (with Mia) was deemed successful overall, we decided to include it in the study. More specific topics during the interviews and examples of questions were: 1) Athlete background (How did you first start out with sports?), and general experiences of coaching and the coach-athlete relationship (What characterises a good coach in your experience?) 2) The specific coach-athlete relationship (How did the intimate and sexual relationship develop? What made this particular relationship special or different from other coach-athlete relationships?) 3) The sport context and athlete performance (Did the relationship with your coach affect your performance in any way?) 4) The private context and personal welfare (How would you describe this person as your coach compared with him your boyfriend? How did you reflect upon whether or not to keep your relationship secret?).

The interviews were conducted in Swedish, recorded digitally, and took between one and two hours. The interviews were transcribed verbatim in Swedish shortly after they had taken place. During transcription exchangeable details that could identify the participants or other individuals, as well as specific sports, clubs, locations, and competitions, were anonymised. The participants were asked to read, comment on, and approve the transcribed interviews before the analysis for the purpose "to validate the transcripts, to preserve research ethics, and to empower the interviewees by allowing them control of what was written." (Mero-Jaffe, 2011:231).

Both authors participated in the thematic discourse analysis that followed the general steps outlined by Bryman (2012, see also regarding inter-coder reliability and internal validity and reliability). First, all interview transcripts were reviewed. Second, we discussed the data, identified emerging themes, and developed the analytical framework. Third, we individually coded the data by labelling four preliminary themes that we had discussed. Fourth, we read through each other's coding and discussed themes, coding and further analysis. During this discussion two of the themes (love and sexuality) were reduced to love because the participants talked more explicitly about love than sexuality, but about a form of romantic love that seemed connected to their sexuality (cf. Jackson, 1993). At the same time another theme was created: the intersection of coaching, love, and sexual relationships. The coded transcripts were then merged. Fifth, the data were read to reflect on the other author's coding and on eventual additional coding (of the same or other parts of the data). During this fifth reading, short comments in the margin were made to outline sub-themes as well as 
interpreting experiences and discourses. To present the results, themes were organised and illustrated by quotations. All quotations were translated to English by the authors. We took the themes to express different discourses that were negotiated by the athletes (and the researcher). Analytically, Foucault's version of discourse analysis is principally about scrutinising how subjectivity is performed through inclusion and exclusion, i.e., what is included and excluded as subjects speak their mind (Foucault, 1998). Or put simple, what subjects can say and do from the position ' $I$ '. This is why the themes are designated in terms of first person statements.

\section{Findings}

\section{No pain; no gain in elite-sport}

When articulating their experiences of sports, the participants clearly refer specifically to the elite-sport context. To them elite-sport means going 'all in', or as Mia puts it: 'I didn't give a shit [about anything else], I was gonna be World Champion.' To achieve success elite-athletes must perform their best at all times, but especially to be the best at the right time.

Competitions are key; that is the time for athletes (teams, clubs and nations) to prove themselves. So simple, yet so difficult. Participants reasoned in an either all (go all in, 100\%, to be the best) or nothing (quit) manner. This feature, the 'all-or-nothing attitude,' constitutes simultaneously exciting challenges and pressures that athletes have to deal with. Liv describes how half of her junior team quit 'because they didn't really cope, while the rest of us advanced to the Junior National Team or became elite-players in the women's league, so ... we who kept going became good, you could say.'

The 'all-or-nothing attitude' informs that athletes need to be prepared to make sacrifices in order to optimise performance and ultimately be the best. The high stakes make the sacrifices desirable and worthwhile. Elite-sport is supposed to be tough to earn its glory. One such sacrifice is that performance takes precedence over health. 'At that high level,' says Ella, 'there is nothing healthy about it, it's just hard all the time.' The athletes seem willing to take on challenges, pressures, and sacrifices, but only if it enhances performance or is a 'sideeffect' of high performance (i.e., 'the other side of the coin').

Although elite-sport is tough and demanding, the participants also emphasised joy, empowerment, and social benefits. Liv describes her team like a family built on trust, kinship, comfort, and a sacred allegiance, and that some of her closest friends are on the National team. As Ella recently retired she looks back on her elite-career with gratitude: 'The travels 
all over the world, all the friends and acquaintances, all the fun you get when you're at that level.' Mia feels empowered: '[S]port has made me comfortable in my body. It's really unique. [...] Like sport has taught me that you can achieve much more than you know. That's outstanding.' Yet, as we will show later, these positive descriptions only partially represent elite-sport. Especially when sexual intimacy enters the picture and sometimes challenges the positive image of elite-sport participation.

Judging by the participants' stories, performance discourse, that is the 'all-or-nothing attitude,' and the close social atmosphere can sometimes create a sense of limitlessness as to what elite-athletes are prepared to do to reach their goals. This might seem extreme, but simply put elite-sport is about constantly pushing the limits that hold athletes back from winning and setting records. Discourses of performance enhancement in elite-sport is therefore an important feature to take into account in relation to CASR. Other important features are, of course, the norms that frame the role of the coach.

\section{The coach needs to know what is right for me}

Elite-sport is socially organised to facilitate athlete performance. Coaches and athletes have certain responsibilities, roles, and expectations to fulfil in order to meet the purported values and aspirations of elite-sport. Our participants described the high demands they have on their coaches. Ella, for instance, 'actually sat down and had like almost an interrogation with him' to ensure that the coach met her expectations and needs. These clear requirements are integral to the expectations among the athletes that coaches should inspire motivation, drive, and confidence in their athletes. Mia says she was convinced she could 'actually win any competition because I trained with him', and moreover that her coach had an extraordinary ability to 'make people accomplish what they thought they couldn't.'

In Mia's eyes, special measures beyond the ordinary are required for the coaches to, in her words, 'create World Champions.' Further, she believes that coach-athlete relationships should be really tight to be good, for you to be best-best.' Such special requirements may include coach-elite-athlete relationships to intersect the professional and private spheres. Mia says, for example, her coach told her things like: 'Don't go out partying tonight,' 'Go to bed now,' 'Are you really gonna eat that?' Mia did not object because her coach 'never had like a typical professional level' - he 'just meant well', 'wanted her to succeed', and was overall an incredible coach in her eyes. 
For coaching to be effective (i.e., to enhance athlete performance), the athletes expect and require their coaches' to be superior to them. Liv, for instance, stresses that a coach 'needs to be the boss' and not 'too kind' because a 'coach who gives the players too much freedom [...] ends up with them [the players] just taking and taking - that doesn't work.' Having said that, coaches' authority, power, and control are multifaceted. Participants did not depict coaches as intimidating or bullies, but as persons who implement a clear, honest, correct, and fair leadership. Coaches' power and authority over athletes is motivated by performance enhancement. Ella, for example, describes her relationship to her coach as essentially equal, them 'needing each-other just as much', but 'if I have a bad day and am tired I have like told him to put his foot down so that I can shape up instead.' The condition that coaches need to be in a superior position in relation to their athletes, however, only holds if the coaches are entrusted to act out of care, concern, and competence with the athletes' performances and careers at heart. Thus, in a well-functioning coach-athlete relationship the athlete obeys the coach because the coach act in (what they believe to be) athletes' best interest - even though it might not always be immediate or obviously apparent to the athletes. Thus, when Mia's coach yelled and was highly demanding she 'read it as though he cared a lot about me.' She later learned, however, that there can be liabilities to this kind of relationship: 'I got the idea that he [the coach] has all the answers. He knows everything. But we function together too, and cooperate [...] I got the idea that everything was owed to him, to his credit.'

The participants voice a discourse where the power and authority, especially expressed as knowledge and moral supervision (the need to tell the athletes to 'shape up'), invested in the coaches is effective, and deliberate from the part of the athletes, as long as the coaches are taken to act in the name of the athletes' wellbeing and performance enhancement. This conscious and purposeful hierarchical relationship seems, however, to poorly match common discourses about romantic love and sexual relationships.

\section{I couldn't help it; I fell in love with him}

Our participants voice views on romantic love (and to some extent (hetero)sexuality) when describing what defines 'boyfriend material' and 'life-partner criteria,' for example, care, commitment, honesty, masculinity, good looks (but not 'too good looking'), compatible values and lifestyles, age, social status, and resources. Liv describes her coach husband like: 
He wasn't really like this man I had pictured to marry. [...] He is like kinder than me and to what thought I prefer (laughter). [...] I thought I would meet someone that was more like ... not authoritarian, because he is, but ... or no, he isn't on a personal level. But I thought I was gonna find more like ... I don't know, testosterone or manly or blah blah blah, but that is in his leadership abilities instead. [...] Then I thought he was a bit old actually ... should have been too old, but he was just almost too old in my eyes.

Apparently, the coach that Liv fell in love with did not really meet her expectations of a prospective partner. The fact that she did fall in love with him illustrates the unexpected, irrational, and uncontrollable force that can be experienced when falling in love. Mia and Anna also describe powerful emotions of romantic love that were impossible to resist. Even though their common sense told them those men were inappropriate as boyfriends, they fantasised about a kind of 'happily ever after' love against the odds:

\footnotetext{
Mia: The second you meet him, you know that this is not a guy you can trust. This is not boyfriend material. It's not ... someone you can trust anywhere. It's a fickle-minded person. Something really attractive about that. [...] It's simply not a person to fall in love with and on top of that he has a girlfriend. [...] Simultaneously being unreachable but yet ... I don't know, a way that worked on me. [...] I was thinking like this: 'this might be him; the guy I'm gonna marry'.
}

Anna: I guess I felt somehow from the beginning, or early on, that if it was security and that package I was looking for, then it was not with him, even if I hoped and like dreamed about it. [...] I was just so in love that I couldn't help acting upon those feelings.

In the participants' stories, sexual desire and romantic love seems to exist within a tension between what is experienced as 'exciting' and 'safe' in relation to social conventions and power dimensions. Liv, Mia, and Anna describe excitement and passion towards a (figurative) forbidden sexual liaison — of falling in love with a person whom they desire despite of and because he is an 'unreachable,' superior, atypical boyfriend. To be able to attract such an elevated persona as a coach can be flattering and might even be experienced as a 'conquest' or as Liv put it: 'What I thought was fun was that it was him. [...] I thought it was fun with like conquests.' The appeal of being 'special' in the coach's eyes relates to coaches' role, position, status, and authority. The athletes thus position themselves as subjects expressing their sexual agency. As Liv indicates above and Anna below, the coaches' power and professional status can amplify their attraction, making them even more desirable to the athletes: 
There is some sort of excitement to it. And to receive love and be special to that person. [...] I have like thought several times that I can find coaches attractive because they are that-coaches. Not as I fall in love, but there is something about that and to me as... novice or what to call it. And that includes persons I would never even look at would it be another situation. How like that thing cast some attractive shimmer... sort of.

As Liv's relationship progressed, however, the initial attraction, excitement, and thrill developed into romantic love for the person behind the role and status of the coach. Liv emphasised that a serious, i.e., safe, couple-relationship is recognised as committed and longterm. It was particularly important for her to emphasise the seriousness of her private relationship because of the coach-athlete relationship. For that purpose marriage and family have a symbolic value, but that was not the primary reason Liv emphasises:

I believe that we wanted to do the right thing because we wanted to be married as Emma's [their child] parents. Then also I know that somehow I like the idea of us not being ... boyfriend and girlfriend, we are spouses; a serious marriage. It's not just a fling. But the big step was really having a child. That mark was distinguishing enough.

Anna addresses another reason why she found it necessary to emphasise her girlfriendboyfriend relationship as serious; the risk of getting a 'slut reputation' for having 'too many' sexual relations. Anna also felt a need to emphasise that she as a female athlete "was there [in sports] for the right reasons.' She continues:

I believe that... especially as a girl, that [sexual relations] can spark a certain reputation and create problems and drama... and talk. Like... disturbs the training... I believe that is worse for girls. And it's mostly guys at the club. So even more then, that you just want to be one in the group. But I guess it's like that everywhere, how girls and guys can act and what is talked about. And I want to be there as an athlete, not someone who chases guys (laughter).

\section{He is my coach - but he is also my partner}

Norms typically associated with the role as coach and boyfriend, girlfriend, spouse, or sexpartner, respectively, are in many aspects distinctly different. The athletes are sometimes adamant in pointing this out:

Anna: On the [gym] mat we were never boyfriend and girlfriend. We never talked about technique at the dinner-table or practiced in bed (laughter). [...] If he'd say 'go get me a glass of water', like a demand [at 
home], I would assume he joked. And he would never do that either. But if he'd tell me to do 20 push-ups during training, I would do it without a thought, sort of ...

Liv: These roles are like sacred. When we enter the hall, then it is those roles. We used to joke about that I'm the coach at home, and it's a bit like that. Yeah, it's like my house sort of, I decide what we eat and ... those sort of things. And otherwise it's Tim [the coach]. It really feels like that when we are in [the sport] situation, where he really is the one making the decisions and I am the player.

According to the above statements, the dimensions and exercise of power differs, depending on context. Ideally, the athletes want to (be able to) distinguish between the private and professional contexts. At the same time, elite-sport is not just a hobby, but something ingrained in their life. In addition, CASR constitute yet another challenge to the professional/private division as CASR often intersect these contexts and at times athletes may benefit from such intersection. For example, the division is challenged since CASR can boost motivation and performance, and in this sense such dual relationships are rational within an elite-sport discourse. Mia says her coach wanted to help her, as a gifted athlete, to succeed; she thus became a 'special athlete,' something she 'appreciated of course' and 'obviously something you don't turn down if you want to win.' Liv describes that she felt sort of 'chosen' by the coach. This aspect may seem purely positive, but as we will show below there are other sides to it.

All athletes felt that they had to lie about their CASR and keep them secret for fear of negative consequences. For example, the athletes (and coaches) were worried about causing 'drama,' disruption, and speculations in the club, team, or group, or were afraid that the coach would get fired (because likely he rather than her would be held responsible). Mia kept her CASR secret to this day, Ella and Liv for about a year (a few of Ella's closest friends and family knew though), and Anna for a few months. To keep the CASR closeted was clearly a stressful, impractical, and harmful experience:

Ella: You want to be open when you're in a relationship, you don't want to keep it a secret. [...] We both agreed on keeping it a secret. At the same time you don't want that. So it's really hard.

Mia: I had like one personality during practice. The one I was in front of everyone there. Then after practice I was something else between him and me. Then when I got home I was like... totally shattered because... partly you were exhausted from hard training, partly you were drained because you knew you were about to get your heart broken. Or how to say it... disappointed... like mentally washed-out. 
Our participants describe the age-gap to be a non-issue to them within their established relationships, but that age-appropriateness stereotypes do not speak in favour of their age dynamic. A more obvious dilemma with the CASR though, is the chance to spark suspicions that the coach's girlfriend receives certain advantages or special treatment. Liv describes that 'as soon I had a bad game someone could say that I play too much, and that I play too much because we are married.' To try to avoid such speculations and accusations she needs to constantly perform at her very best, which is obviously stressful.

Although our participants have all faced difficulties associated with their CASR, they have no regrets engaging in these dual relationships (although Mia's hope for more than an affair was never fulfilled). The athletes involved in couples-relationships (Anna, Ella, Liv) emphasise love to be their number one priority. Ella explains: 'Sports don't last a lifetime, but I want to live with him forever.' Liv says she and her coach/partner were 'prepared for one of us to quit the National team' and that they 'knew there was a great chance of that, but we were simply on board.' In addition, none of the participants believe that CASR should—or likely could - be prohibited. Liv states that it would not 'have made any difference if it was prohibited by any policy or not.' Ella says: 'When you're in love, it's so hard to stop. I mean if these feelings are mutual and recognised, it doesn't matter if it's written on a piece of paper that you shouldn't have a relationship.' To Anna, it is a personal matter because 'we were not children ... that's one thing ... we didn't harm anyone. Like I would have been angry if someone would forbid me, so ... I would've done it anyway, been with him.' In this sense keeping CASR a secret seems in the eyes of the athletes, primarily to be about giving into the mysterious and irrational force of romantic love, albeit without interfering with the ordered and rational sport practice.

\section{Concluding discussion}

The analysis indicates that the athletes' modes of subjectification (Foucault, 1982; see also Foucault, 1977; 1979) include normalising a careful balancing between sport performance enhancement discourse (rational, hierarchical, coach-centred) and romantic love discourse (emotional, reciprocal), but that this balance is at times difficult to maintain. This is particularly so when the athletes consider what they believe that others would have to say about their relationship. The athletes' experiences of CASR include characteristics of wellfunctioning coach-athlete relationships such as increased motivation, effective training, trust, comfort, and understanding (Jowett and Poczwardowski, 2007). They also include problems 
and dilemmas, especially related to the intersection of (sometimes contradictive) discourses of elite-sport, coaching, and romantic love.

Discourses on inherent power inequalities between coaches and athletes, where the coach occupies the position as the 'centre of sports' (cf. Parameswara, 1985), can frame CASR as inappropriate, unethical, unprofessional, harmful, and abusive. Yet the athletes' stories illustrate a more multidimensional picture of power in CASR. The female athletes experience that they can recognise consensual, mutually desired CASR. Furthermore, the athletes actively (contribute to) uphold coaches power by expecting, sometimes explicitly demanding, their coaches to implement dominance and control because coaches' power functions as a driving force to enhance performance. In the private relationship context, however, power is manifested differently. Romantic love relationships are more about mutually giving up some power and control, or giving in to the force of love- 'the bolt from the blue' (Sarsby, 1983: 5).

The athletes describe a type of 'rational self' that corresponds to conventional modes of subjectification in sport and the wider socio-cultural context (cf. Toftegaard Nielsen, 2001). At the same time the powerful emotions of love constitute the means, force, and motives to simultaneously break boundaries and give up control and independency to 'follow the heart.' When love is experienced as mutual and recognised by both parties, the athletes say that they prioritise love above all - if necessary even before their athlete career. Although none of the participants had to make such a choice, this illustrates the significance of romantic love in this context. The athletes' describe furthermore how power inequities can spark sexual desire and romantic love. At the same time, these exciting and 'forbidden' liaisons imply social risk for the female athletes, for example a 'slut-stigma.' Discourses intersecting love, gender, and (hetero)sexuality are informed by different sets of unwritten rules for women and men in sports and society. As emphasised by Jackson (1993), the force attributed to love is more complex than the mere link between mutual affection and free choice of partner.

Overall, the athletes seem aware of that CASR deviate from social conventions. They deal with this deviance in different ways. First, the athletes describe making conscious decisions to transgress norms, often as a result of 'having enough' of being in a situation that causes them and their CASR harm. One obvious example of such agency is to engage in CASR in the first place. Such decision seem to be based upon whether the potential benefits, especially related to mutual, long-term love, are expected to exceed the social and professional risk-taking that can accompany these boundary transgressions. For example, 
being in love may facilitate both happiness and motivation while a 'broken heart' can have the opposite effect. Second, to make the CASR appear less deviant and socially disruptive, features representing equality, interdependency, and conformity with cultural institutions and social norms are emphasised. The athletes also try to overachieve, show dedication, and loyalty to their peers to prove they are one of them and that their CASR do not negate performance enhancement. Third, the coach-athlete couples have felt it necessary to employ certain precautions and restrictions in their interaction as professionals and partners to (try to) avoid problems caused by their CASR. Such measures include keeping (exaggerated) distance in sport situations and to lie about or hide certain things.

A common restriction is to keep the CASR closeted. We believe this inclination has something to do with that coach-athlete relationships, often characterised by age difference, are conventionally considered to be unequal, while sexual and romantic love relationshipsbetween people of the same age - are, ideally, equal. Furthermore, the more deviant the relationship according to social context; the more reason for secrecy to prevent stigmatisation and other negative outcomes. Discourses of performance enhancement in elite-sport and coaching may frame sexual relationships between coaches and athletes as particularly deviant; a violation of the fundamental, sacred values and morals of sport, the ideally ordered coachathlete relationship, and coaches as guardians of these ideals (cf. Brackenridge, 2001). Secret, marginalised sexual relationships can be unhealthy and cause vulnerability to begin with (cf. Lehmiller, 2012; Powell and Foley, 1998; Sikes, 2006). The athletes' accounts illustrate more specifically how they negotiate dominating discourses within sport and the coach-athlete relationship, which can be destructive and force athletes and coaches involved in sexual relationships into secrecy and isolationism. For Ella and Mia, the secrecy became unhealthy, stressful, and ultimately affected their whole life situation. Mia could accept sacrifices that enhanced sport performance, but when the CASR started to negatively affect her ability to perform she recognised a need to break up the sexual relationship with her coach.

It is a complex but nonetheless important matter to socially and regulatory protect athletes from harm and abuse in coach-athlete relationships. Like our participants, we are inclined to believe that CASR cannot be legislated away by regulatory or moral prohibitions. Foucault (1979) suggests, moreover, that prohibition may well contribute to perform the behaviour that prohibition is taken to prevent. Hence, good intentions to prevent sexual abuse by principally condemning CASR may (unintentionally) discourage transparency and reasoned debate, contribute to taboos and isolation rather than protecting athletes or hinder 
CASR from occurring. In addition, denouncing relationships perceived as consensual and loving as abuse can feel hurtful, unfair, and unimaginable.

To conclude, the athletes' subjective experiences unfold in the intersection between discourses of performance enhancement in elite sport and coaching (e.g., all-or-nothing attitude and rational training to enhance performance) and romantic love (e.g., an irresistible, partly irrational force and socio-cultural institution). Hence, CASR should not be discussed as either sexual relationships or coach-athlete relationships and power in CASR needs to be understood in relation to the intersection of agency and social structure. Discourses provide guidance through which social conventions are negotiated in certain directions depending on the context, and can be both fulfilled and challenged by individual agency - even at the same time. Romantic love can, for example, be one reason for an athlete to 'follow her heart' instead of the dominant discourses on elite-sport, which simultaneously is exactly what a discourse on romantic love guides her to do.

In this study we explored how a number of specific discourses framed our participants' experiences of the CASR they had engaged in with their coaches. Thus, the confines of these particular discourses, athletes, relationships, and interviews constitutes limitations of this study, which has not been performed for the purpose of generalisation. We found that even CASR that are legal, consensual, and mutually desired can cause harm and dilemmas because they challenge traditional normative notions, purported moral standards and the status quo of sports. CASR as deviant raises speculations, conflicts, social repression, and dilemmas that can affect all concerned parties but result in stigmatisation, isolation, and thus vulnerability of the athlete-coach couple in particular. We stress that such problems must be addressed.

Similar to Sikes (2006), we found that problems had more to do with privileged discourses of power and abuse, and thus the socially repressive response, than problems within the CASR themselves. In that sense, prohibiting CASR is (just) another normative response, rather than prevention or a solution to empower and protect athletes. Since repression contributes to reproducing the coach as the centre of sports, attempts to increase athlete agency would then be to de-centre the role of coaches. Consequently, more research on CASR is needed to inform theory, policy, and practice. For example regarding the complexity of sexual consent relating broadly to dimensions of agency, structure, and power, and specifically to age, gender, sexuality, and the coach-athlete relationship. Moreover, all facets of positive and negative characteristics and consequences of CASR need to be unfolded and 
comprehensively investigated. Other implications for further research that we suggest include scientific investigations, interventions, and programs to develop and implement policy and codes of practice to manage CASR, prevent harmful and abusive coach-athlete relationships, and to improve education, ethical awareness, dialogue, and transparency within sport. These implications also extend to a larger context of protection, safety, and health in sport and beyond; fear of harmful touch, paedophilia, sexual misconduct, and abuse that cast coaches and other male authorities as potential sexual predators (cf. (Piper et al., 2012; Sikes, 2006, 2010; Taylor et al., 2014).

\section{References}

Anderson E (2010) Sport, Theory and Social Problems. A Critical Introduction. London: Routledge.

American Psychological Association (APA) (2010) Ethical Principles of Psychologists and Code of Conduct. Available at: http://www.apa.org/ethics/code/index.aspx (accessed 14 December 2015).

Bailey R (2006) Physical Education and Sport in Schools: A Review of Benefits and Outcomes. Journal of School Health, 76(8): 397-401.

Biskup C and Pfister G (1999) I Would Like to be Like Her/Him: Are Athletes

Role-Models for Boys and Girls? European Physical Education Review, 5(3): 199-218.

Brackenridge CH (2001) Spoilsports: Understanding and preventing sexual exploitation in sport. London: Routledge.

Brake DL (2012) Going Outside Title IX to Keep Coach-Athlete Relationships in Bounds. Marquette Sports Law Review, 22, 394-425.

Bringer JD Brackenridge CH and Johnston LH (2002) Defining appropriateness in coachathlete sexual relationships: The voice of coaches. Journal of Sexual Aggression, 8(2): 83-98. Brown WJ Basil MD and Bocarnea MC (2003) The Influence of Famous Athletes on Health Beliefs and Practices: Mark McGwire, Child Abuse Prevention, and Androstenedione. Journal of Health Communication, 8(1): 41-58.

Bryman A (2012) Social Research Methods. Oxford: Oxford University Press. Fasting K Brackenridge CH and Sundgot-Borgen J (2003) Experiences of Sexual Harassment and Abuse among Norwegian Elite Female Athletes and Non-Athletes. Research Quarterly for Exercise and Sport, 74(1): 84-97. 
Fasting K and Sand TS (2015) Narratives of sexual harassment experiences in sport. Qualitative Research in Sport, Exercise and Health, 7(5): 573-588.

Felmlee DH and Sprecher S (2006) Love. In: Stets JE and Turner JH (eds) Handbook of the Sociology of Emotions. New York: Springer, pp. 389-409.

Foucault M (1977) Discipline and Punish. The birth of the prison. New York: Pantheon. Foucault M (1979) The History of Sexuality. Vol. 1. An Introduction. London: Allen Lane. Foucault M (1982) The subject and power. In: Dreyfus H and Rabinow P (eds) Michel Foucault. Beyond Structuralism and Hermeneutics. New York: Harvester Wheatsheaf, pp. 308-326.

Foucault M (1998) Essential works of Foucault, 1954-1984. Vol. 2, Aesthetics, method and epistemology. New York: New Press.

Garratt D Piper H and Taylor B (2013) 'Safeguarding' sports coaching: Foucault, genealogy and critique. Sport, Education and Society, 18(5): 615-629.

Hartill M (2009) The Sexual Abuse of Boys in Organized Male Sports. Men and Masculinities, 12(2): 225-249.

Houlihan B (2010) Policy convergence in elite sport development: A critical review of the evidence. Key-note lecture, European Association for Sport Management, Prague, 11-18 Sept. International Council for Coaching Excellence (ICCE) (2012) Codes of Conduct for Coaches. Available at: $\underline{\text { http://www.icce.ws/_assets/files/projects/Codes_of_Conduct_2012_study.pdf }}$ (accessed 26 September 2015).

Jackson S (1993) Even Sociologists Fall in Love: An Exploration in the Sociology of Emotions. Sociology, 27(2): 201-220.

Jackson S (2001) Happily Never After: Young Women's Stories of Abuse in Heterosexual Love Relationships. Feminism\& Psychology, 11(3): 305-321.

Johansson S (2013) Coach-Athlete Sexual Relationships: If No Means No Does Yes Mean Yes? Sport, Education and Society, 18(5): 678-693.

Johns DP and Johns JS (2000) Surveillance, Subjectivism and Technologies of Power. An Analysis of the Discursive Practice of High-Performance Sport. International Review of the Sociology of Sport, 35(2): 219-234.

Jowett S and Poczwardowski A (2007) Understanding the Coach-Athlete Relationship. In: Jowett S and Lavalee D (eds) Social Psychology in Sport. Champaign: Human Kinetics, pp. 314. 
Kenttä G (2014) Being a female elite athlete: a psychological perspective. Women and Sport, 3.3. Stockholm: SISU and World Village of Women Sports.

Kirby S Greaves L and Hankivsky O (2000) The dome of silence. Sexual harassment and abuse in sport. Halifax: Fernwood Publishing.

Lane AJ (2006) Gender, Power, and Sexuality: First, Do No Harm. Chronicle of Higher Education, 52(35): 10-13.

Larsson H (2001) Iscensättningen av kön i idrott: en nutidshistoria om idrottsmannen och idrottskvinnan (The social construction of gender in sport. A history of the present of the sports man and the sports woman). PhD Dissertation, HLS förlag, Stockholm.

Larsson H (2014) Materialising bodies: there is nothing more material than a socially constructed body. Sport, Education and Society, 19(5), 637-651.

Leahy T Pretty G and Tenenbaum G (2002) Prevalence of Sexual Abuse in Organised Competitive Sport in Australia. Journal of Sexual Aggression, 8(2): 16-36.

Lee R (1993) Doing research on sensitive topics. London: Sage.

Lehmiller J (2012) Perceived marginalization and its association with physical and psychological health. Journal of Social and Personal Relationships, 29(4): 451-469.

Mero-Jaffe I (2011) 'Is that what I said?' Interview transcript approval by participants: An aspect of ethics in qualitative research. International Journal of Qualitative Methods, 10 : 231-247.

Moran C and Lee C (2014) Women's constructions of heterosexual non-romantic sex and the implications for sexual health. Psychology \& Sexuality, 5(2): 161-182.

Nicholls A (2013) Effective Leadership in Sport. Peak Performance, 320: 9-13.

Norberg JR (1997) A mutual dependency: Nordic sports organizations and the state. The International Journal of the History of Sport, 14(3): 115-135.

Parameswara RN (1985) Coach is the center of sports. International Journal of Physical Education, 22(1): 16-20.

Piper H Taylor B and Garratt D (2012) Sports coaching in risk society: No touch! No trust! Sport, Education and Society, 17: 331-345.

Powel GN and Foley S (1998) Something to Talk About: Romantic Relationships in Organizational Settings. Journal of Management, 24: 421-448.

Renzetti C and R Lee (1993) Researching sensitive topics. London: Sage. 
Safe4Athltetes (2013) Handbook. Local Sport Club Policies and Procedures. Available at: http://safe4athletes.org/component/k2/item/31-safe4athletes-handbook (accessed 26 September 2015).

Sarsby J (1983) Romantic Love and Society. Harmondsworth: Penguin.

Sikes P (2006) Scandalous Stories and Dangerous Liaisons: When Female Pupils and Male Teachers Fall in Love. Sex Education: Sexuality, Society and Learning, 6(3): 265-280.

Sikes P (2010) Teacher-Student Sexual Relations: Key Risks and Ethical Issues. Ethnography and Education, 5(2): 143-157.

Soucie D (1994) Effective Managerial Leadership in Sport Organizations. Journal of Sport Management, 8: 1-13.

Stirling A and Kerr G (2009) Abused athletes' perceptions of the coach-athlete relationship. Sport in Society, 12(2): 227-239.

Taylor WG and Garratt D (2010) The professionalisation of sports coaching: Relations of power, resistance and compliance. Sport, Education and Society, 15: 121-139.

Taylor WG Piper H and Garratt D (2014) Sports coaches as 'dangerous individuals'Practice as governmentality. Sport, Education and Society, Available at: http://dx.doi.org/10.1080/13573322.2014.899492.

SSC (2012) Sport in Sweden. Stockholm: The Swedish Sports Confederation.

Toftegaard Nielsen J (2001) The Forbidden Zone. Intimacy, Sexual Relations and Misconduct in the Relationship between Coaches and Athletes. International Review for the Sociology of Sport, 36: 165-182.

Toftegaard Støckel J (2010) Athlete perceptions and experiences of sexual abuse in intimate coach-athlete relationships. In: Brackenridge $\mathrm{CH}$ and Rhind D (eds) Elite Child Athlete Welfare: International perspectives. London: Brunel University Press, pp. 93-100.

Williams CL Giuffre PA and Dellinger K (1999) Sexuality in the workplace: Organizational Control, Sexual Harassment, and the Pursuit of Pleasure. Annual Review of Sociology, 25: 7393. 
Table 1: Participants

\begin{tabular}{llllll}
\hline & $\begin{array}{l}\text { Sport: } \\
\text { Individual } \\
\text { /Team }\end{array}$ & Age & $\begin{array}{l}\text { Coach's } \\
\text { circa age }\end{array}$ & $\begin{array}{l}\text { Career: } \\
\text { Ongoing } \\
\text { /Retired }\end{array}$ & CASR \\
\hline Mia & I & 29 & 40 & $\mathrm{O}$ & $\begin{array}{l}\text { Ended unattached sexual relationship, coach } \\
\text { engaged with girlfriend }\end{array}$ \\
Anna & $\mathrm{I}$ & 30 & 35 & $\mathrm{R}$ & $\begin{array}{l}\text { Ended boyfriend-girlfriend relationship } \\
\text { Ella }\end{array}$ \\
I & 26 & 35 & $\mathrm{R}$ & On-going boyfriend-girlfriend relationship \\
Liv & $\mathrm{T}$ & 27 & 40 & $\mathrm{O}$ & On-going marriage and one child together \\
\hline
\end{tabular}

